\title{
Paciente crítico e comunicação: visão de familiares sobre sua adequação pela equipe de enfermagem
}

\author{
THE CRITICAL PATIENT AND COMMUNICATION: \\ THE VISION OF THE FAMILY REGARDING THE NURSING TEAM
}

\author{
EL PACIENTE CRÍTICO Y LACOMUNICACIÓN: \\ VISIÓN DE LOS FAMILIARES SOBRE SU ADECUACIÓN POR EL EQUIPO DE ENFERMERÍA
}

\author{
Luciana Cintra Inaba', Maria Júlia Paes da Silva², Sandra Cristina Ribeiro Telles ${ }^{3}$
}

\begin{abstract}
RESUMO
A comunicação é considerada importante variável no cuidado do paciente crítico e de sua família, cuja dificuldade em se comunicar é expressa na literatura. $\mathrm{O}$ objetivo da pesquisa foi verificar o que é comunicação adequada com a equipe de enfermagem na percepção do familiar do paciente crítico. Estudo exploratório e de campo, realizado na UTI do Hospital Universitário da USP. A população constituiu-se de 13 familiares de pacientes internados. Os dados foram coletados em novembro de 2003 e analisados, segundo a proposta de Bardin. Foi considerada comunicação adequada aquela em que a comunicação é um meio de informação - as informações são claras e objetivas, há esclarecimento de dúvidas, há orientações; e a comunicação é uma forma de tornar o cuidado mais humanizado - havendo comunicação verbal mesmo com o paciente sedado, tendo alguém como referência para que os familiares possam recorrer.
\end{abstract}

\section{DESCRITORES}

Comunicação.

Relações profissional-família.

Família.

Equipe de enfermagem.

Unidades de terapia intensiva.

\begin{abstract}
Communication is considered an important variable in the care of critical patients and their families, whose difficulty concerning communication is expressed in the literature. The purpose of this survey was to verify what is considered adequate communication with the nursing team in the perception of the critical patient's family. This is an exploratory and field study carried out at the Intensive Care Unit of the University of São Paulo's Hospital Universitário. The population surveyed was comprised of 13 relatives of critical patients. The data was collected in November of 2003 and analyzed according to Bardin proposal. Communication was considered adequate when it was a means for information - the information was clear and objective, doubts were clarified, orientation was provided and communication was a form of humanizing health care - and there was verbal communication even when the patient was sedated, with somebody as a reference whom the relatives could resort to.
\end{abstract}

\section{KEY WORDS}

Comunication.

Professional family relations.

Family.

Nursing team.

Intensive care units.

\section{RESUMEN}

La comunicación es considerada una importante variable en el cuidado del paciente crítico y de su familia, cuya dificultad para comunicarse es expresada en la literatura. El objetivo de esta investigación fue verificar qué es comunicación adecuada con el equipo de enfermería en la percepción del familiar del paciente crítico. Se trata de un estudio exploratorio, descriptivo y de campo, realizado en la UCI del Hospital Universitario de la USP. La población se constituyó de 13 familiares de pacientes internados. Los datos fueron recolectados en noviembre del 2003 y analizados según la propuesta de Bardin (1977). Se consideró comunicación adecuada a aquella donde la comunicación es un medio de información - las informaciones son claras y objetivas, hay aclaraciones de dudas, orientaciones; y la comunicación es una forma de tornar el cuidado más humanizado - habiendo comunicación verbal aunque el paciente esté sedado, teniendo a alguien como referencia a donde los familiares puedan recurrir.

\section{DESCRIPTORES}

Comunicación.

Relaciones profesional-familia.

Familia.

Grupo de enfermería.

Unidade de terapia intensiva.
1 Enfermeira da UTI do Hospital Universitário da Universidade de São Paulo (HU/USP). Graduada pela Escola de Enfermagem da Universidade de São Paulo (EEUSP).

lucianainaba@hotmail.com

2 Professora Livre-Docente do Departamento de Enfermagem MedicoCirúrgica da EEUSP. juliaps@usp.br

3 Enfermeira Chefe da Unidade de Terapia Intensiva do HU/USP. sa.telles@zipmail.com 


\section{INTRODUÇÃO}

Ao longo da graduação, uma das autoras do artigo constatou o quanto a comunicação é importante para a vida das pessoas, principalmente para os enfermeiros, outros profissionais da saúde e também para os pacientes e seus familiares. Somente pela comunicação efetiva é que o profissional pode ajudar o paciente a conceituar seus problemas, enfrentá-los, visualizar sua participação na experiência e alternativas de solução dos mesmos, além de auxiliá-lo a encontrar novos padrões de comportamento $^{(1)}$.

O cuidar é feito com o outro e não apenas um procedimento, uma intervenção técnica, mas uma relação de ajuda, que envolve respeito, compreensão e $\mathrm{o}$ uso do toque de forma mais efetiva ${ }^{(2)}$. Infere-se que se o cuidado é feito com o outro, a comunicação adequada é fundamental, principalmente no cuidado com os pacientes críticos e terminais. Comunicação adequada é aquela apropriada a uma determinada situação, pessoa, tempo e que atinge um objetivo defini$\mathrm{do}^{(1)}$. Existem dois tipos de comunicação: a verbal e a não-verbal, sendo que a comunicação verbal referese às palavras expressas por meio da fala ou escrita $\mathrm{e}$ a não-verbal ocorre por meio de gestos, silêncio, expressões faciais, postura corporal...(1).

Em um estudo realizado com enfermeiras que cuidam de lesados medulares, verificou-se que a comunicação verbal é melhor compreendida que a comunicação não-verbal, porque esta não é sempre percebida conscientemente pela equipe de Enfermagem $^{(3)}$. Porém, a atenção à comunicação não-verbal é essencial ao cuidado humano, por resgatar a capacidade do profissional de saúde de perceber, com maior precisão, os sentimentos do paciente, suas dúvidas e dificuldades de verbalização, além de ajudar a potencializar sua própria comunicação ${ }^{(1)}$. É urgente a necessidade dos enfermeiros conhecerem ou resgatarem a comunicação não-verbal emitida por eles e pelos pacientes, como maneira de entender melhor o que acontece nas relações entre enfermeiro e paciente ${ }^{(4)}$.

Além disso, a comunicação não-verbal é uma das bases nos cuidados paliativos, que são os cuidados prestados aos pacientes cuja enfermidade não responde mais aos tratamentos curativos, e que precisam de qualidade de vida, enquanto ela durar ${ }^{(5)}$. A dor e outros sintomas são expressos pela comunicação verbal e não-verbal ${ }^{(1,5)}$. É também por meio da comunicação que o ser humano pode satisfazer suas necessidades de inclusão, controle e afeição, sendo que a inclusão refere-se a aceitação pelo outro, o controle ocorre quando se experimenta a sensação de ser responsável e capaz de se adaptar ao meio e a afeição diz respeito a necessidade de expressar e receber amor $^{(6)}$.

A comunicação é um aspecto importante ao atendimento de pacientes críticos e o enfermeiro pode, se tiver um bom contato, uma boa comunicação com a família, estabelecer um melhor cuidado ${ }^{(7)}$. Contribui para a excelência da prática da Enfermagem e cria oportunidades de aprendizagem para o paciente, podendo despertar o sentimento de confiança entre paciente e enfermeiro, permitindo que ele experimente a sensação de segurança e satisfação ${ }^{(6)}$.

A dificuldade de comunicação faz com que a necessidade de cuidados seja aumentada. O paciente ao enfrentar a situação de não poder se comunicar com alguém, necessita de auxílio e atenção redobrados da equipe no seu cuidado ${ }^{(8)}$. A ansiedade, o desconforto e a insegurança sentidas pelos pacientes críticos, podem ser maximizados para aqueles cuja capacidade de comunicação se encontra limitada ${ }^{(8)}$

Se os cuidados são redobrados aos pacientes críticos, principalmente os com deficiência na comunicação, mesmo que temporariamente, a presença da família é muito importante para aliviar a ansiedade, o desconforto e a insegurança citadas. O profissional de saúde não pode, de maneira alguma, negar o núcleo no qual o paciente vive, e o familiar é muito importante para que se possa entendê-lo e, por essa razão, ajudar na tarefa de reequilibrar e reharmonizar o doente ${ }^{(9)}$.

Neste trabalho, a família é entendida como pessoas aparentadas que vivem na mesma casa, como um conjunto de gêneros afins ${ }^{(10)}$.

Além de dar apoio ao paciente, a família pode oferecer as informações necessárias para um melhor cuidado, pois decodifica os gostos, manias, expressões dos pacientes com restrição de comunicação verbal; e esses dados podem ser essenciais aos cuidados de Enfermagem ${ }^{(11)}$.

Outros autores acreditam na importância da presença do familiar ao lado do paciente e afirmam que a evidência teórica, prática e investigacional do significado que a família dá para o bem estar e a saúde de seus membros, bem como a influência sobre a doença, obriga os enfermeiros a considerar o cuidado centrado na família como parte integrante da prática de Enfermagem ${ }^{(12)}$. Os pacientes relatam que os problemas sentidos por eles e suas expectativas em relação à equipe de Enfermagem recaem mais na área expressiva, pois queixam-se da separação da família, do ambiente desconhecido e agressivo, da 
quebra nos hábitos de alimentação e hidratação, do medo de morrer, da dependência de outrem, do desrespeito à privacidade e da falta de atenção individualizada $^{(11)}$.

Além disso, é importante que a família participe no cuidado dos pacientes terminais. $\mathrm{O}$ morrer possui cinco estágios: a negação, a ira, a barganha, a depressão e a aceitação ${ }^{(13)}$. A família pode proporcionar serenidade ao paciente e, caberá ao pessoal de saúde introduzí-la na assistência ao paciente, orientando-os sobre cada estágio ${ }^{(14)}$.

Um estudo realizado em cinco hospitais gerais de Belo Horizonte, verificou as necessidades de cuidados de Enfermagem na assistência ao paciente terminal e referiu que a necessidade de comunicação representou o maior percentual na categoria de necessidades psicossociais; que tanto a comunicação verbal quanto a não-verbal são essenciais para o relacionamento humano e auxiliam o paciente nas fases do processo morrer, citadas anteriormente ${ }^{(15)}$.

O contato estreito da família com o sujeito hospitalizado, além de benéfico para este, diminui o sentimento de desamparo do familiar diante do sofrimento desse indivíduo ${ }^{(16)}$. Além disso, segundo as mesmas autoras, a família deve, e tem amparo legal, ser informada das condições de saúde de seu familiar, como também pode participar ativamente desse processo.

As famílias dos pacientes necessitam também de cuidados e não devem ser vistas como um auxílio "técnico" ao trabalho de Enfermagem, mas como indivíduos a serem cuidados também pela Enferma$\mathrm{gem}^{(16)}$. Para que a família cumpra o seu papel de dar suporte à situação vivenciada pelo paciente, também precisa de suporte nas suas necessidades físicas e emocionais, como uma conversa esclarecedora, uma cadeira extra para que o familiar possa ficar tocando seu ente querido, um cafezinho num momento mais crítico ${ }^{(11)}$.

Entretanto, se observou que os profissionais de saúde não assumem que cuidam das famílias, que são responsáveis por elas, lembrando que as famílias também correm riscos de doenças físicas, além da insegurança, irritabilidade, que comprometem a sua capacidade de decisão e de auxílio ao seu ente querido ${ }^{(17)}$.

Devido a importância da inserção da família no cuidado do paciente crítico e considerando o quanto esta necessita dos cuidados de Enfermagem, principalmente de uma comunicação adequada com a equipe, é que surgiu a motivação para realizar este estudo com a finalidade de conhecer a real necessidade de comunicação das famílias dos pacientes críticos e de alertar os profissionais de Enfermagem para a importância dos cuidados com a família deste tipo de paciente, lembrando que cuidar é a essência da Enfermagem e que só pode-se exercê-la se o fizermos com conhecimento científico, ética e, acima de tudo, amor ${ }^{(7)}$.

\section{OBJETIVO}

Verificar o que é comunicação adequada com a equipe de Enfermagem na percepção do familiar do paciente crítico.

\section{MÉTODO}

\section{Tipo de estudo}

O estudo é do tipo exploratório e de campo. Neste tipo de estudo o pesquisador aprofunda seus estudos nos limites de uma realidade específica, buscando antecedentes e maiores conhecimentos para, em seguida, planejar uma pesquisa descritiva que é um estudo caracterizado pela necessidade de se explorar uma situação não conhecida, da qual se tem necessidade de maiores informações ${ }^{(18)}$.

Foi realizado um levantamento da realidade da população escolhida por ser necessário saber a opinião destas pessoas para conseguir atingir o objetivo do presente estudo. Um pesquisador de campo deseja aproximar-se das pessoas estudadas de modo a compreender uma situação, a partir de seu cenário natural, sem uma estrutura ou controle por ele imposto $^{(19)}$.

\section{Local de inquérito}

O estudo foi realizado na Unidade de Terapia Intensiva do Hospital Universitário da Universidade de São Paulo. Trata-se de um hospital-escola público de grande porte da cidade de São Paulo, que conta com 12 leitos e 63 profissionais de Enfermagem no seu quadro de pessoal.

\section{Sujeitos da pesquisa}

Foram entrevistados 13 familiares de pacientes internados na Unidade de Terapia Intensiva há pelo menos três dias e que aceitaram participar do estudo. O número total de familiares entrevistados dependeu da compreensão do fenômeno estudado.

\section{Aspectos éticos $e$ \\ Procedimentos de coleta de dados}

$\left.1^{\circ}\right)$ Solicitada autorização para a Comissão de Ética e Pesquisa da Instituição envolvida; $2^{\circ}$ ) Após
Paciente crítico e comunicação: visão de familiares sobre sua adequação pela equipe de enfermagem 
Luciana Cintra Inaba Maria Júlia Paes da Silva Sandra Cristina R. Telles aprovação, solicitada autorização dos familiares para serem entrevistados, antes do horário de visita. Entregue uma carta de apresentação, no qual foi apresentado o título da pesquisa, o objetivo e foi solicitada a colaboração para participar do estudo. Nesta carta estava explicado que o entrevistado poderia desistir de participar do estudo a qualquer momento e que as informações seriam mantidas em absoluto sigilo e anonimato. O local e o horário foram escolhidos pelos próprios sujeitos da pesquisa. $3^{\circ}$ ) Solicitado autorização ao entrevistado para gravar a entrevista, que continha as seguintes perguntas norteadoras: 1) Na sua opinião, como deveria ser a comunicação ideal da equipe de Enfermagem responsável pelo cuidado do paciente internado na UTI, com a família deste? 2) O que é comunicação com a equipe de Enfermagem? Além destas questões, constou das entrevistas dados como: idade, sexo, grau de parentesco, experiência anterior com parentes internados na UTI e grau de escolaridade do entrevistado.

\section{Tratamento de dados}

Os dados foram transcritos e analisados segundo a proposta de análise de conteúdo de $\operatorname{Bardin}^{(20)}$. Segundo este autor, a análise de conteúdo é um conjunto de técnicas de análise das comunicações, e organiza-se em três pólos cronológicos: a pré análise, a exploração do material e o tratamento dos resultados, a inferência e a interpretação ${ }^{(20)}$. Propõe a codificação e a categorização do material coletado. A primeira corresponde

a uma transformação dos dados brutos do texto que por recorte, agregação e enumeração permite atingir uma representação do conteúdo.

A segunda corresponde

a uma operação de classificação de elementos constitutivos de um conjunto, por diferenciação e, seguidamente, por reagrupamento segundo o gênero, com os critérios previamente definidos.

Para realizar a análise de conteúdo, há um conjunto de técnicas que podem ser utilizadas, como: a análise categorial, a análise de avaliação, de enunciação, de expressão, das relações e análise de discurso $^{(20)}$. No presente estudo, utilizou-se a análise categorial que funciona por operações de desmembramento do texto em unidades, em categorias segundo reagrupamentos analógicos.

\section{APRESENTAÇÃOE ANÁLISE DOS DADOS}

Foram realizadas 13 entrevistas com familiares, sendo 9 mulheres e 4 homens. A idade dos entre- vistados variou entre 24 e 61 anos, tendo como média 45 anos. Do total de entrevistados, cinco eram filhos do paciente, três eram irmãos, duas eram cunhadas, duas eram esposas e um era marido. Apenas quatro já haviam tido experiência anterior com internação de familiares em UTI. O nível de escolaridade variou entre analfabeto e nível superior completo, porém na classificação dos dados, não foram identificadas diferenças na essência das respostas obtidas.

\section{Categoria 1: Comunicação como meio de informação}

Quando questionados sobre o que seria comunicação, 12 (n total 13) afirmaram que é conversar com alguém.

Comunicação é a gente poder conversar, fazer perguntas sobre o paciente e não manter aquela distância que geralmente existe entre as pessoas. (E5)

Fica explícita que a comunicação permite que pacientes e familiares sintam satisfação e segurança aos serem cuidados pelos enfermeiros ${ }^{(6)}$.

Os familiares consideram que a comunicação adequada é aquela em que as informações sobre o estado do paciente acontecem nos horários da visita e são transmitidas de uma maneira simples, clara e objetiva, sem o uso de termos difíceis, para a compreensão até de pessoas com menos escolaridade.

Quando às vezes minha mãe vem, ela leva o recado tudo ao contrário pra gente, ela falava uma coisa e era outra. (E10)

Para um melhor esclarecimento das explicações é importante repetirmos as informações aos familiares.

... quando a gente não entende, eles chegam e falam de novo. (E10)

A importância das orientações e do contato direto do enfermeiro com o familiar aparece em quase todos os discursos. Segundo esses familiares, a equipe de Enfermagem deveria explicar melhor o que está acontecendo, as informações do dia, a evolução do paciente, o porquê da urina estar colúrica ou porque o paciente está edemaciado, o que significa estar “estável".

Quando dizem: ele está regular, pra mim regular pode ser tanta coisa... . (E2)

Além disso, relatam que orientar o familiar também é muito importante.

... semana passada eu viajei, quando eu cheguei, estava o papelzinho escrito lá, aí eu olhei aquilo ali e vi que tinha que colocar luva, tinha que ter avental e eu não sabia se era para os enfermeiros ou se era para nós... . (E3) 
Devido à estas orientações e explicações dadas, a comunicação da equipe de Enfermagem com o familiar foi considerada muito importante

... se você chega e vê ele intubado, enfiado numa máquina aqui, outra ali, você não sabe o que é aquela máquina, não sabe o que aquela máquina está fazendo, então é super importante o relacionamento da Enfermagem com a família do paciente. (E2)

Quando faltam informações, eles ficam perdidos, sem saber para quem perguntar e o que fazer.

Tem pessoas leigas que entram já chorando e em desespero porque não foram orientadas. (E2)

Afirmam ter dificuldades em ter acesso a quem detém as informações e que o ideal seria ter uma central de informações, uma pessoa que saiba de cada caso para poder transmitir aos familiares. Parece importante a Enfermagem estar presente durante a visita dos familiares aos pacientes, explicando os cuidados do dia, os problemas de Enfermagem e esclarecendo as dúvidas dos familiares.

... geralmente se determina um horário para o médico falar com você e nos demais horários de visita há um silêncio. (E1)

As falas anteriores reforçam o encontrado por outros autores de que é importante conversar e orientar os familiares, esclarecer sobre as rotinas, a impossibilidade de uma acomodação adequada para o acompanhante, atender suas necessidades e expectativas, orientar sobre como o familiar poderia ajudar e a quem recorrer em caso de dúvidas ${ }^{(17)}$.

Alguns familiares afirmam ter medo e receio de fazer perguntas e saber algo que não gostariam.

Eu não fiz pergunta nenhuma, estou com medo e receosa, prefiro não saber. (E4)

Em contrapartida, outros relataram estar dispostos a saber sobre o estado de seu familiar e enfrentar a situação.

Se for grave ou o que seja, eu estou aqui para saber. (E9)

Além do paciente, a família pode apresentar as cinco fases percebidas em situação de perda (negação, ira, barganha, depressão e aceitação) e necessita de assistência neste período; precisa de um ser humano que o deixe falar, chorar ou gritar, se necessário $^{(13)}$. Nos exemplos citados, encontramos a negação e a aceitação, respectivamente.

Nessa categoria fica claro que comunicação adequada é um processo de compreender, compartilhar mensagens enviadas e recebidas, sendo que as próprias mensagens e o modo como ocorre o intercâmbio exercem influência no comportamento nas pessoas nele envolvidas, como já referendado em literatura ${ }^{(6)}$

A comunicação é tida como algo muito importante para a família porque consideram que é a ligação com o saber sobre o estado do paciente. A maioria referiu preferir que as informações sejam verdadeiras e transmitidas sem mentiras.

É falar tudo com certeza e com verdade. (E11)

Queixam-se quando há um silêncio da equipe de Enfermagem.

Quando falam pra mim: olha, eu não posso falar nada, isto é muito ruim. (E1)

A própria capacidade de afeto empático, de colocar-se no lugar de outra pessoa, leva as pessoas a seguir certos princípios morais como a justiça e a verdade $^{(21)}$. Então, a empatia é fundamental para a comunicação adequada já que nos leva à seguir o caminho da verdade.

Definem, portanto, comunicação adequada como a recepção de informações daquilo que o indivíduo quer saber, fazer as perguntas e obter as respostas, receber notícias. Além disso, relatam que é imprescindível que o enfermeiro entenda aquilo que o familiar está perguntando e vice-versa.

\section{Categoria 2:}

\section{Comunicação como cuidado mais humanizado}

Oito (n total 13) também relacionaram o bom atendimento com a boa comunicação.

O ideal seria como está sendo aqui, o pessoal daqui atende muito bem... as enfermeiras tratam a gente como se fizesse parte da família. (E5)

Nessa fala fica explícita a dimensão humana do cuidar, onde o familiar também se sente cuidado, incluso ao meio, respeitado e acolhido ${ }^{(2,6,9)}$.

Afirmam que o familiar sofre até mais que o internado e que certos comunicados os deixam apavorados.

A gente sabe que é grave, ela está na UTI justamente porque é grave e toda a esperança está dentro daquela UTI . (E1)

Por isso, acreditam que o ideal seria que as enfermeiras proporcionassem conforto aos familiares e dessem atenção a eles, conversassem, acalmassem e esclarecessem as dúvidas existentes.
Paciente crítico e comunicação: visão de familiares sobre sua adequação pela equipe de enfermagem 
Luciana Cintra Inaba Maria Júlia Paes da Silva Sandra Cristina R. Telles
O internado está sedado, e o parente está aqui todo dia, então você vem acompanhando e você quer, às vezes, na verdade, até um conforto. (E1)

Quanto mais o clima for de conforto e confiança, mais a experiência pode ser positiva porque os gestos de atenção e cuidado ficarão presentes sempre na lembrança dos familiares ${ }^{(11-12)}$.

Alguns relatam vivenciar com a equipe de Enfermagem um relacionamento seco e técnico, na maioria das vezes, sem humanização. Para esses entrevistados, o ideal seria que existisse um relacionamento mais humano e maleável.

Deveria ter um curso de relacionamento humano, de tratar das pessoas de uma maneira mais elegante. (E1)

Essa fala confirma dados anteriores ${ }^{(1,3)}$ que apontam para a importância da equipe de Enfermagem resgatar mais conscientemente a comunicação nãoverbal, que é a dimensão da comunicação que qualifica as relações, permitindo a demonstração dos sentimentos e a verificação da coerência dos nossos gestos e posturas no estar com as pessoas.

Os familiares afirmam que tratar dos pacientes com carinho, acariciando-os, conversando com eles, mesmo estando sedados, hidratá-los e fazer a higiene diária, fazem parte de uma comunicação ideal.

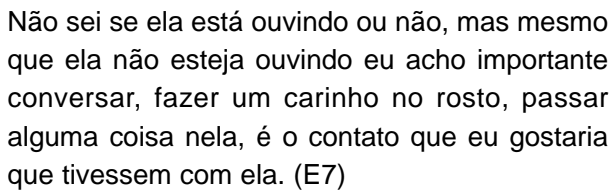

Já foi verificado que a comunicação com o paciente sedado é necessária, é reconhecida como função do enfermeiro, é algo que o diferencia como profissional e, algumas vezes, infelizmente, o contato com o paciente sedado é um ato condicionado, sem reflexão ${ }^{(22)}$.

Além disso, referem que a enfermeira deve ter paciência com o paciente e com o familiar. Cumprimentar e sorrir, colocar o paciente em primeiro lugar, esquecendo os problemas pessoais.

... o problema é a enfermeira que não está bem em casa. A boa enfermeira, mesmo que esteja com algum problema, ela deixa os problemas em casa e o paciente fica em primeiro lugar. (E6)

Todos nós possuímos autoconsciência que identifica e nomeia nossas emoções despertadas e mantém a autoreflexividade, mesmo em meio a emoções turbulentas ${ }^{(21)}$. Se conhecermos e aceitarmos as nossas próprias emoções, conseguiremos controlá-las e as impediremos de prejudicar a assistência ao familiar.
Alguns ressaltam a importância da comunicação não-verbal na comunicação com os familiares.

Não adianta só falar, a sua expressão já acaba amenizando e tranqüilizando a gente. (E8)

Em estudo realizado em um hospital privado, verificaram que a comunicação verbal e não-verbal influenciam o comportamento das pessoas e promovem a satisfação dos pacientes com a assistência de Enfermagem ${ }^{(23)}$. É bom lembrar também a importância de estarmos atentos à percepção correta da comunicação não-verbal porque nem sempre a mensagem não-verbal tem o mesmo significado para diferentes pessoas e situações, exigindo validação verbal da compreensão dos sinais não-verbais percebidos ${ }^{(1)}$.

Houve entrevistados que não souberam definir comunicação:

Eu não sei responder a esta pergunta, sou analfabeta, entende? (E4)

mas se colocaram quanto a maneira como deve ocorrer a comunicação adequada entre a equipe e os familiares.

Pra mim está de acordo. Fui bem atendida. Prefiro não perguntar mais nada, eu prefiro não saber. (E4)

Nessa fala, surge novamente a negação, um dos estágios possíveis de serem encontrados nos processos de perda ${ }^{(13)}$.

Vale ressaltar, portanto, que o enfermeiro consegue cuidar da família quando for capaz de perceber que é por meio de retroalimentações que esses indivíduos buscam seu equilíbrio ${ }^{(24)}$.

Seria bom se tivesse alguém em todos os horários, todas as horas, alguém que conversasse com a gente. (E1)

\section{CONCLUSÕESE CONSIDERAÇÕES FINAIS}

Comunicação adequada para os familiares é conversar e receber informações pertinentes ao que o indivíduo quer saber; é entender o que o outro quer transmitir e sentir-se bem atendido, tratado também com carinho e paciência. É aquela em que há informações claras e objetivas; há explicações sobre o estado do paciente e sobre os equipamentos, sondas, catéteres e drenos nele existentes. Existe a necessidade das famílias de se comunicar com a equipe de Enfermagem durante os horários de visita, receber orientações e esclarecer dúvidas, assim como, ter satisfeita sua necessidade de conforto, receber palavras carinhosas e atenção. 
Além disso, verifica-se que existe a percepção da coerência ou não da comunicação não-verbal pelos familiares, principalmente das expressões faciais e do toque. A preocupação deles com o cuidado de seu ente querido em relação a higiene, hidratação da pele e comunicação verbal, mesmo que sedado, foi exemplificado como comunicação adequada.

Há necessidade de alguém da equipe de Enfermagem ser referência para os familiares; alguém a quem eles possam recorrer para uma conversa, es- clarecimento de suas dúvidas e ser tranqüilizados e orientados.

O cuidar, inclusive do familiar, implica em perceber o outro como ele se mostra, nos seus gestos e falas, em seus conceitos e limitações. Não é suficiente deixar a família entrar na UTI, é necessário cuidá-la para potencializar nosso trabalho na Enfermagem; é preciso questioná-la sobre as dúvidas, observar-lhe as reações e comportamentos, entenderlhe as emoções.

\section{REFERÊNCIAS}

(1) Silva MJP. Comunicação tem remédio: a comunicação nas relações interpessoais em saúde. $4^{\mathrm{a}}$ ed. São Paulo: Gente; 1996.

(2) Waldow VR. Cuidado humano: o resgate necessário. Porto Alegre: Artes Médicas; 1998.

(3) Inaba LC, Silva MJP. A importância e as dificuldades da comunicação verbal e não-verbal no cuidado dos deficientes físicos. Nursing 2002; 5(51):20-4. (edição brasileira)

(4) Silva MJP. O toque e a distância interpessoal entre enfermeiros e pacientes nas consultas de enfermagem. Rev Esc Enferm USP 1991; 25(3):309-18.

(5) McCoughlan M. A necessidade de cuidados paliativos. O Mundo da Saúde 2003; 27(1):6-14.

(6) Stefanelli MC. Comunicação com o paciente: teoria e ensino. $2^{a}$ ed. São Paulo: Robe; 1993.

(7) Rodrigues IG, Zago MMF. Enfermagem em cuidados paliativos. O Mundo da Saúde 2003; 27(1):89-92.

(8) Kimura M. Problemas dos pacientes de Unidade de Terapia Intensiva: estudo comparativo entre pacientes e enfermeiros. [dissertação] São Paulo (SP): Escola de Enfermagem da USP; 1984.

(9) Silva MJP. O amor é o caminho: maneiras de cuidar. $2^{\text {a }}$ ed. São Paulo: Gente; 2000.

(10) Ferreira ABH. Novo dicionário da língua portuguesa. Rio de Janeiro: Nova Fronteira; 1993.

(11) Silva MJP. Humanização em UTI. In: Cintra EA, Nishide VM, Nunes WA. Assistência de enfermagem ao paciente crítico. São Paulo: Atheneu; 2000. p. 1-11.

(12) Wright LM, Leahey M. Enfermeiras e famílias: um guia para avaliação e intervenção na família. $3^{\mathrm{a}} \mathrm{ed}$. São Paulo: Roca; 2002.

(13) Klüber-Ross E. Sobre a morte e o morrer. São Paulo: Edart; 1981.
(14) Boemer MR. Assistência a pacientes terminais. Rev Paul Hosp 1983; 31(1/2):33-7.

(15) Ferraz AF, Carvalho DV, Costa TMPF, Carvalho WS. Assistência de enfermagem a pacientes em fase terminal. Rev Bras Enferm 1986; 36(1):50-60.

(16) Nascimento ERP, Martins JJ. Reflexões acerca do trabalho da enfermagem em UTI e a relação deste com o indivíduo hospitalizado e sua família. Nursing 2000; 3(29):26-30. (edição brasileira)

(17) Shiotsu CH, Takahashi RT. O acompanhante na instituição hospitalar: significado e percepções. Rev Esc Enferm USP 2000; 34(1):99-107.

(18) Leopardi MT. Metodologia da pesquisa na saúde. Santa Maria: Pallotti; 2001.

(19) Polit DF, Hungler BP. Fundamentos de pesquisa em enfermagem. $3^{\mathrm{a}}$ ed. Porto Alegre: Artes Médicas; 1995.

(20) Bardin L. Análise de conteúdo. Lisboa: Edições 70 1977.

(21) Goleman D. Inteligência emocional: a teoria revolucionária que redefine o que é ser inteligente. $3^{\mathrm{a}} \mathrm{ed}$. Rio de Janeiro: Objetiva; 1995.

(22) Zinn GR, Silva MJP, Telles SCR. Comunicar -se com o paciente sedado: vivência de quem cuida. Rev Lat Am Enferm 2003; 11(3):326-32.

(23) Santos KMAB, Silva MJP. Pacientes idosos e sua percepção da comunicação verbal e não-verbal com a equipe de saúde em uma instituição hospitalar. Rev Paul Enferm 2003; 22(1):43-50.

(24) Wernet M, Ângelo M. Mobilizando-se para a família: dando um novo sentido à família e ao cuidar. Rev Esc Enferm USP 2003; 37(1):19-25.
Paciente crítico e comunicação: visão de familiares sobre sua adequação pela equipe de enfermagem
Correspondência: Luciana Cintra Inaba Rua Itamiami, 131 - Ap. 14 Vila Mariana - São Paulo CEP - 04120-100- SP 